\title{
ФИЗИЧЕСКАЯ ХИМИЯ
}

УДК 544.4

\section{КИНЕТИКА ХИМИЧЕСКИХ ПРОЦЕССОВ В МОЗГЕ ЧЕЛОВЕКА. ТРИГГЕР-ЭФФЕКТ И АВТОСТАБИЛИЗАЦИЯ N-АЦЕТИЛАСПАРАГИНОВОЙ КИСЛОТЫ}

\author{
Член-корреспондент РАН С. Д. Варфоломеев ${ }^{1}$,
}

\author{
Н. А. Семенова ${ }^{2}$, В. И. Быков ${ }^{2, *}$, С. Б. Цыбенова ${ }^{2}$
}

Поступило 01.08.2018 г.

\begin{abstract}
Предложена кинетическая модель процесса ответа нервной ткани на внешнее сигнальное воздействие. Модель основана на представлении о многостадийности и нелинейности динамического процесса изменений концентрации N-ацетиласпарагиновой кислоты и N-ацетиласпартата в нервной ткани человека. Эффект ингибирования субстратом для этой системы является необходимым фактором автостабилизации N-ацетиласпартата как ключевого метаболита мозга. Существование трёх стационарных состояний объясняет триггерное поведение системы.

Ключевые слова: мозг человека, химические процессы, кинетика, триггер-эффект, N-ацетиласпарагиновая кислота.
\end{abstract}

DOI: https://doi.org/10.31857/S0869-56524844441-446

Современные физические методы позволяют наблюдать протекание химических реакций in vivo в таких сложных объектах, как мозг человека. Эти возможности определяются в первую очередь развитой техникой магнитно-резонансной томографии (МРТ) и ЯМР-спектроскопии. Эти методы позволяют выделять и анализировать структурные образования в мозге in vivo, параллельно и независимо идентифицировать отдельные химические соединения и их концентрации $[1,2]$.

Одним из наиболее загадочных соединений мозга является $\mathrm{N}$-ацетиласпарагиновая кислота (N-ацетиласпартат). $\mathrm{N}$-ацетиласпартат является биомаркером нейронов мозга. Это соединение отсутствует в других органах и тканях человека и животных. Уровень концентрации $\mathrm{N}$-ацетиласпартата в разных отделах и органах мозга различен, однако это соединение везде представлено в наибольших концентрациях по сравнению с другими метаболитами. В силу этого $\mathrm{N}$-ацетиласпартат хорошо детектируется ЯМР-спектроскопией in vivo [3].

Роль $\mathrm{N}$-ацетиласпартата в метаболизме мозга не выяснена. Одним из относительно новых методов является метод функциональной

\footnotetext{
${ }^{1}$ Московский государственный университет им. М.В. Ломоносова

${ }^{2}$ Институт биохимической физики им. Н.М. Эмануэля Российской Академии наук, Москва

*E-mail:vibykov@mail.ru
}

магнитно-резонансной томографии (фМРТ), который основан на детектировании локального изменения контраста в томограммах, вызванного нейрональной активностью.

Выполнение какой-либо задачи вызывает в активированных нагрузкой локусах головного мозга активацию кровотока, лишь частично соответствующую увеличению потребления кислорода [4]. Это приводит к увеличению концентрации оксигемоглобина Нb относительно концентрации дезоксигемоглобина dHb. Последний является МРТ-контрастом, снижающим время спин-спиновой релаксации протонов тканевой воды. Таким образом, изменение соотношения [Hb]/[dHb] создаёт контраст, который зависит от степени насыщения крови кислородом (blood oxygenation level, BOLD-контраст) и опосредованно характеризует активность нейронов.

В МРТ-изображениях BOLD визуализируется как локальные изменения контрастности в течение 1-16 с после воздействия стимула. Это позволяет определить локусы, активирующиеся в ответ на стимул, и установить связи между активацией локусов мозга и последующими биохимическими процессами.

Основанная на регистрации BOLD функциональная МРТ широко используется для выявления зон активности в мозге в норме и при различных заболеваниях центральной нервной системы $[5,6]$. 
Мы использовали BOLD как динамическую характеристику локального изменения соотношения $[\mathrm{Hb}] /[\mathrm{dHb}]$, вызванного активацией нейронов, и попытались связать этот параметр с динамикой нейронального маркера $\mathrm{N}$-ацетиласпартата в активированной зоне мозга с последующим кинетическим моделированием процесса. Такая задача ставится впервые.

Магнитно-резонансные исследования проводили на томографе Achieva Philips 3.0 T (резонансная частота для ядер ${ }^{1} \mathrm{H} 127$ МГц), оснащённом градиентной системой “Dual Quasar”. Использовали восьмиканальную приёмную радиочастотную катушку для головы. Структурные изображения головного мозга получали, используя импульсную последовательность турбополевого эха с релаксационной задержкой TR $=8,2$ мс, временем эхо ТЕ $=3,7$ мс, углом поворота вектора намагниченности $\mathrm{FA}=8^{\circ}$, временем инверсии TI $=1021$ мс, числом эхо 240, фактором ускорения сбора данных SENSE factor $=1,5$, полем обзора $\mathrm{FOV}=240$ мм, числом накопления NSA $=1$.

Для проведения фМРТ-исследования использовали последовательность Т2 EPI; TR $=3000$ мс, $\mathrm{TE}=30$ мс, ЕРІ-фактор $=240$, количество срезов 30 , толщина среза 4 мм, NSA $=1$, число динамик 210 , длительность одной динамики 3 с. Стимуляцию предъявляли испытуемым с использованием приставки Eloquence (“In Vivo-Philips”), применяя звуковой сигнал (тон, частота 1 кГц, громкость звука составляла 70-80 дБ) с последующим нажатием специальной кнопки указательным пальцем правой руки [7].

BOLD-сигнал получали, подавая стимулы с интервалом 18 с. Парадигма исследования состояла из 210 динамик, количество стимулов 30. Для группы испытуемых, состоящей из 9 здоровых мужчин-правшей (средний возраст $22,1 \pm 1,9$ г.) суммировали значения BOLD во временных точках $t=0,3,6,9,12,15,18$ с после выполнения действия; $\operatorname{BOLD}_{(t)}$ нормировали на $\mathrm{BOLD}_{(0)}$.

Спектроскопический воксель размером $20 \times 10 \times 15$ мм располагали в зоне премоторной коры левого полушария, активированной движением пальца. ${ }^{1} \mathrm{H}$ МР-спектры регистрировали с помощью импульсной последовательности PRESS, TE $=30$ мс, TR $=3000$ мс. Для получения спектров, синхронизированных с динамикой BOLD, нами разработана специальная методика динамической спектроскопии, подробно описанная в [7]. Каждому испытуемому стимулы повторяли 98 раз и записывали $98 \times 7$ сигналов спинового эха. Затем сигналы группировали в соответствии с точками BOLD. Таким образом, каждый спектр получен с NSA $=98$. Аналогичным способом получали спектры для состояния покоя, используя те же временные точки, но без подачи стимула.

Для обработки сигналов написали специальную программу, которая включает умножение на экспоненту и функцию Гаусса, преобразование Фурье, коррекцию фазы вручную и измерение амплитуд сигналов. Амплитуды сигналов, измеренные в спектрах для времени $t$, нормировали на значения, измеренные в спектрах для времени $t=0$, и на объём клеток в вокселе, который получали вычитанием объёма цереброспинальной жидкости (определяли вручную на аксиальных T2-взвешенных изображениях, используя программный пакет Extended MR Workspace).

Наблюдаемые кинетические ответы на внешний звуковой сигнал - принятие решения функциональный ответ (нажатие кнопки) относительно изменения концентрации в зонах возбуждения представлены на рис. 1. Ответ BOLD соответствует изменению в исследуемом объёме нейронной ткани концентрации оксигенированного гемоглобина. С некоторой задержкой (периодом индукции) концентрация детектируемого реагента возрастает, через 6 с проходит максимум и возвращается на исходный базовый уровень. Ответ в концентрации N-ацетиласпартата наступает после 5-6 с задержки, при этом наблюдается “антипик" - временное уменьшение концентрации $\mathrm{N}$-ацетиласпартата. Минимальное значение наблюдается на 12-й секунде после звукового сигнала и нажатия кнопки.

С учётом многостадийного биохимического процесса индуцированного расширения сосудов

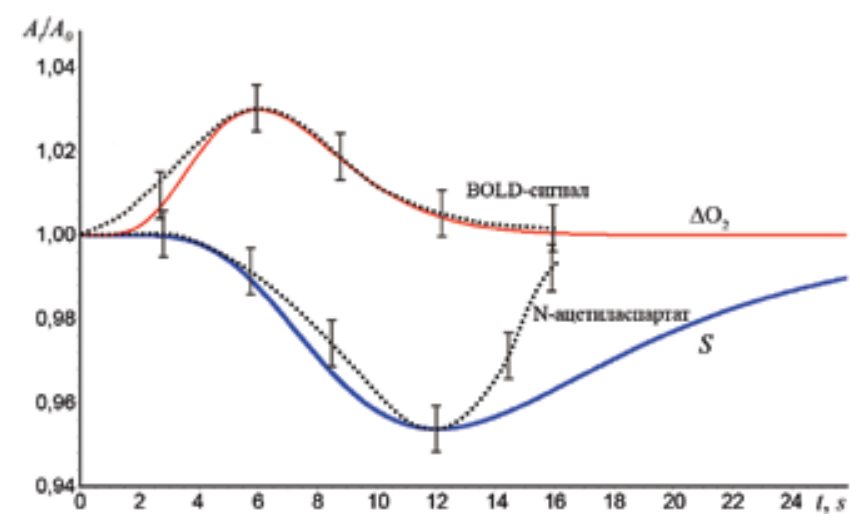

Рис. 1. Экспериментальные и расчётные кривые динамики изменения концентрации $\mathrm{N}$-ацетиласпартаты на внешний сигнал: пунктирные линии - экспериментальные данные: BOLD-сигнал и N-ацетиласпартат; сплошные линии - расчётные линии $\Delta \mathrm{O}_{2}$, $\mathrm{S}$. Результаты эксперимента и моделирования нормированы на амплитуду сигнала $\mathrm{N}$-ацетиласпартата $\left(A_{\mathrm{t}}\right)$ для времени $t=0\left(A_{0}\right)$. 
для описания динамики процесса можно использовать функцию вида

$$
\Delta O_{2}\left(A / A_{0}\right)=A t^{n} \exp (-\xi t) .
$$

Для многостадийных ферментативных реакций с соизмеримыми кинетическими параметрами начальный этап развития процесса может быть описан функцией $t^{n}$, где $n-$ число промежуточных стадий. Релаксация к исходному уровню, связанная с замещением гемоглобина новыми порциями крови, может быть представлена экспоненциальной функцией с параметром $\xi$.

Динамическое уравнение для N-ацетиласпартата можно записать в виде

$$
\frac{d S}{d t}=\alpha\left(S_{0}-S\right)-\beta w(S) \gamma A_{m} \Delta \mathrm{O}_{2}
$$

где член $\alpha\left(S_{0}-S\right)$ характеризует открытую по потоку $\mathrm{S}$ природу процесса, $\beta w(S)$ - скорость гидролиза $\mathrm{S}$ под действием аспартоацилазы, $\gamma A_{\mathrm{m}} \Delta \mathrm{O}_{2}-$ окислительный процесс с участием одного из метаболитов конверсии $\mathrm{S}$.

B простейшем случае возможность участия промежуточных стадий передачи кислорода до взаимодействия с S может быть описана следующей совокупностью превращений:

1) $\mathrm{O}_{2}+\mathrm{A}_{1} \rightarrow \mathrm{A}_{2}$,

2) $A_{2} \rightarrow A_{3}$,

3) $\mathrm{A}_{3}+\mathrm{S} \rightarrow \mathrm{A}_{3} \mathrm{~S}$,

где $\mathrm{A}_{1}, \mathrm{~A}_{2}, \mathrm{~A}_{3}$ - промежуточные вещества. Соответствующая схеме (3) кинетическая модель может быть записана в виде

$$
\begin{aligned}
& \frac{d \mathrm{~A}_{1}}{d t}=-k_{1} \Delta O_{2} \mathrm{~A}_{1}, \\
& \frac{d \mathrm{~A}_{2}}{d t}=k_{1} \Delta O_{2} \cdot \mathrm{A}_{1}-k_{2} \mathrm{~A}_{2}, \\
& \frac{d \mathrm{~A}_{3}}{d t}=k_{2} \mathrm{~A}_{2}-k_{3} \mathrm{~A}_{3} S, \\
& \frac{d S}{d t}=\alpha\left(S_{0}-S\right)-\beta w(S)-k_{3} \mathrm{~A}_{3} S,
\end{aligned}
$$

где $k_{i}, i=1,2,3,-$ константы скоростей стадий схемы (3). Минимальная кинетическая схема (3) позволяет описать ряд промежуточных превращений кислорода до стадии его взаимодействия с субстратом $\mathrm{S}$.

Продукты конверсии $\mathrm{N}$-ацетиласпартата активные метаболиты, принимающие участие в нейробиологических процессах и энергетическом метаболизме. Аспарагиновая кислота $\mathrm{P}_{1}$ является нейромедиатором, а также главным источником глутаминовой кислоты - основного возбуждающего нейромедиатора. За счёт быстрого процесса переаминирования с использованием $\alpha$-кетоглутаровой кислоты образуется глутаминовая кислота $\mathrm{P}_{2}$, последующая конверсия которой ведёт к образованию $\gamma$-аминомасляной кислоты - важнейшего тормозящего нейромедиатора.

В биохимическом плане гидролиз $\mathrm{N}$-ацетиласпартата с образованием аспарагиновой кислоты индуцирует цепь последующих превращений, ведущих к ключевым метаболитам головного мозга.

Следует ещё раз подчеркнуть, что N-ацетиласпартат - один из важнейших участников нейробиологических процессов, его концентрация существенно превышает концентрацию всех аминокислотных метаболитов мозга.

Реакция гидролиза N-ацетиласпартата достаточно хорошо изучена [8]. Характерной особенностью регуляции активности фермента, которая безусловно играет важную роль, является сложная зависимость скорости реакции от концентрации субстрата

$$
w(S)=\frac{a_{0} S^{3}}{b_{0}+b_{1} S+b_{2} S^{2}+b_{3} S^{3}+b_{4} S^{4}} .
$$

Молекулярно-кинетическое исследование этих эффектов на основе QM/MМ приближений дано нами в работах [9-12].

При высоких концентрациях субстрата скорость реакции существенно уменьшается (ингибирование избытком субстрата), при этом важно подчеркнуть, что физиологически наблюдаемая концентрация $\mathrm{N}$-ацетиласпартата в нейронах находится в области существенного подавления активного фермента $\left(b_{0}, b_{1}, b_{2}, b_{3}, b_{4}\right)$. Интегрирование системы уравнений (1)-(5) проведено с использованием специально разработанной программы в среде Delphi Enterprise. Решение кинетической модели позволяет визуализировать динамические ответы по всем переменным и исследовать поведение системы при варьировании параметров.

Предложенная кинетическая модель достаточно адекватно описывает экспериментальные данные (рис. 1), включая “затяжки” на кинетических стадиях накопления продуктов и “антипике” N-ацетиласпартата. Точность эксперимента не позволяет определить значения параметров процесса, можно лишь сделать оценки диапазонов, при которых “затяжки” достаточно качественно описываются моделью. Оценки параметра $n$ (число стадий, предшествующие “выбросу” кислорода) лежат в диапазоне 4-8, параметра $m$ (число стадий, предшествующих окислению S) - в диапазоне 4-12. 
Кривые, приведённые на рис. 1, являются решением системы уравнений (1)-(5) при следующих значениях параметров: $\alpha=6 ; \beta=1 ; A=0,135 \cdot 10^{-5}$; $\xi=1 ; n=6 ; S_{0}=0,008 ; k_{1}=11,5 ; k_{2}=0,14 ; k_{3}=102 ;$ $a_{0}=0,248 ; b_{0}=1,8 \cdot 10^{-13} ; b_{1}=9 \cdot 10^{-9} ; b_{2}=4,5 \cdot 10^{-4}$; $b_{3}=2 ; b_{4}=2,44 \cdot 10^{3}$. Значения $a_{0}, b_{0}, b_{1}, b_{2}, b_{3}$ и $b_{4}$ определены из экспериментальных данных в соответствии с [8-12]. Важно отметить, что максимальное значение концентрация кислорода достигает на 6-й секунде после внешнего раздражителя, минимальное значение $\mathrm{N}$-ацетиласпартата - на 12-й секунде. Через 30-35 с концентрация $\mathrm{N}$-ацетиласпартата практически достигает исходного стационарного уровня.

Обладая достаточно адекватной кинетической моделью, основанной на биохимических данных, можно ответить на ключевые вопросы, дающие представление о поведении "загадочной” $\mathrm{N}$-ацетиласпартат-системы:

1) каков механизм автостабилизации концентрации $\mathrm{N}$-ацетиласпартата как ключевого метаболита мозга и какова роль в этом процессе эффекта ингибирования активности аспартоацилазы избытком субстрата?

2) каковы динамические ответы в поведении последующих в цепи превращения метаболитов (аспарагиновой кислоты, уксусной кислоты, глутаминовой кислоты) после “волны” гидролиза $\mathrm{N}$-ацетиласпартата и соответствующего образования продуктов?

Известно, что эффект ингибирования избытком субстрата в открытой системе с вводом вещества $\mathrm{S}$ в концентрации $S_{0}$ и выводом его из

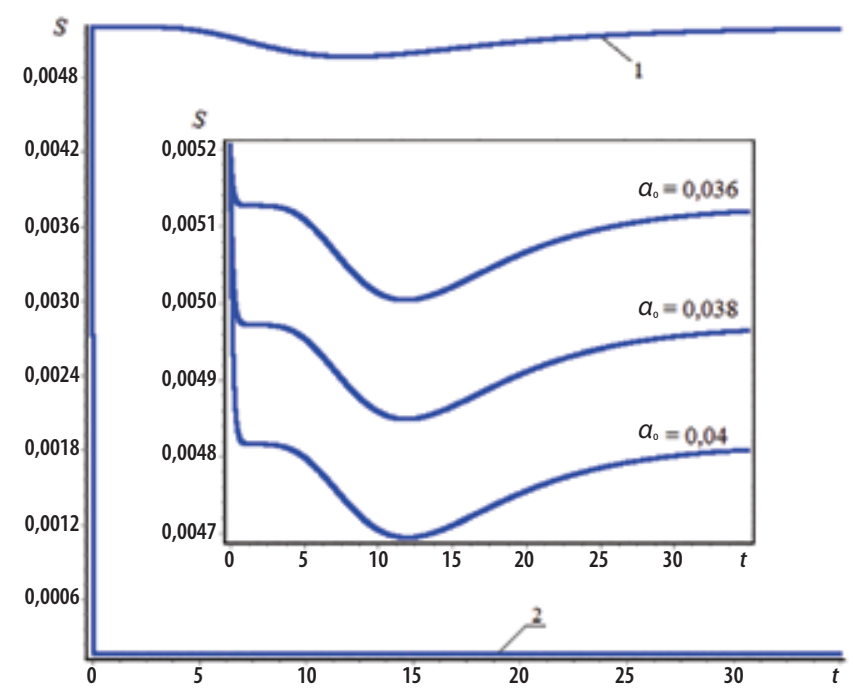

Рис. 2. Динамические ответы системы в присутствии (1) и отсутствии (2) эффекта ингибирования субстратом $\left(b_{4}=0\right)$ и при варьировании значений $a_{0}$ Каталитической активности фермента (уравнение (4)). системы с концентрацией $S$ ведёт к образованию по крайней мере трёх стационарных состояний $[13,14]$.

В отсутствие эффекта ингибирования субстратом система неспособна выйти на исходный устойчивый стационарный уровень концентрации $\mathrm{N}$-ацетиласпартата. На рис. 2 представлены ответы системы в присутствии (кривая 1) и отсутствии эффекта ингибирования субстратом (в уравнении (5) $b_{4}=0$, кривая 2), а также при различных значениях каталитической активности фермента $a_{0}$. Теоретически в отсутствие ингибирования субстратом $\left(b_{4}=0\right)$ концентрация $\mathrm{N}$-ацетиласпартата резко падает и его стационарная концентрация очень мала (кривая 2).

Вывод исследования: эффект ингибирования субстратом для данной системы является необходимым фактором автостабилизации $\mathrm{N}$-ацетиласпартата как ключевого метаболита мозга.

Аспарагиновая кислота является нейромедиатором, однако наиболее яркая её роль - трансформация в глутаминовую кислоту - основного нейромедиатора значительной доли нервных клеток. Образование аспарагиновой кислоты Asp и ацетата строго стехиометрично расходу $\mathrm{N}$-ацетиласпартата. В динамической модели в уравнении (2) скорость расхода $(-\beta w(S))$ изменяет знак на положительный:

$$
\frac{d \mathrm{Asp}}{d t}=\alpha\left(S_{0}-S\right)+\beta w(S)-\delta \mathrm{Asp},
$$

где $\delta$ Asp - трансформация аспарагиновой кислоты в глутаминовую,

$$
\frac{d G l u}{d t}=\delta \mathrm{Asp}-\varepsilon \mathrm{Glu},
$$

где $\varepsilon \cdot \mathrm{Glu}-$ скорость трансформации Glu в дальнейшем метаболизме.

Результаты численного интегрирования уравнений (1)-(8) представлены на рис. 3 (динамика изменения аспарагиновой кислоты и динамика изменения глутаминовой кислоты) при значениях параметров $\delta=10 ; \varepsilon=0,3$.

Важно подчеркнуть, что автостабилизация концентрации Asp, как и Glu, определяется процессом ингибирования субстратом аспартоацилазы.

Кинетическая модель, развитая в данной работе, количественно описывает наблюдаемые динамические ответы. Принципиально важным является объяснение эффекта автостабилизации концентрации $\mathrm{N}$-ацетиласпартата и последующих метаболитов. Этот эффект связан с особенностью кинетического действия фермента, а именно с ингибированием каталитической активности фермента при высоких концентрациях 


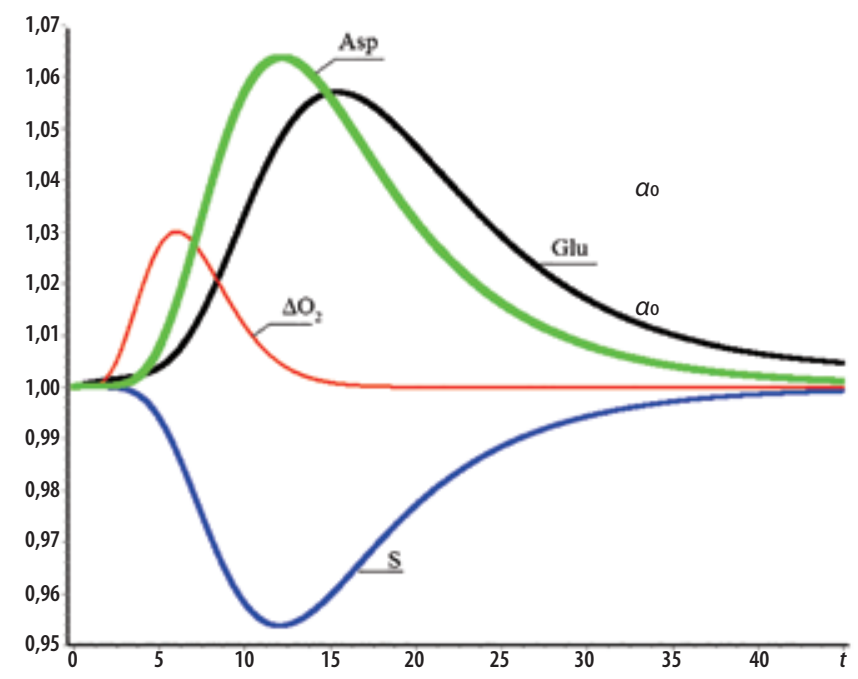

Рис. 3. Теоретические кривые изменения концентрации аспарагиновой Asp и глутаминовой Glu кислот, кислорода $\Delta \mathrm{O}_{2}$ и $\mathrm{N}$-ацетиласпартаты $\mathrm{S}$ в соответствии с решениями уравнений (1)-(5), (7), (8).

$\mathrm{N}$-ацетиласпартата. Для данной системы характерно наличие двух устойчивых стационарных состояний, при этом наибольшим запасом прочности обладает стационарное состояние с высоким уровнем $\mathrm{N}$-ацетиласпартата. Нормой являются стационарные состояния с высоким уровнем N-aцетиласпартата (аспартоацилаза ингибирована большой концентрацией $\mathrm{N}$-ацетиласпартата). Переход системы во второе устойчивое стационарное состояние (низкий уровень $\mathrm{N}$-ацетиласпартата и высокая активность аспартоацилазы) может быть связан с потерей нейронами функциональной активности, например при черепно-мозговой травме.

Кинетическое моделирование позволяет предсказать поведение метаболитов, определение концентраций которых in vivo затруднено. В результате "антипика" $\mathrm{N}$-ацетиласпартата возникает волна продуктов его гидролиза - аспарагиновой и уксусной кислот. $\mathrm{N}$-ацетиласпартат - уникальный метаболит, продукт гидролиза, который участвует в двух системах - в энергетической и нейромедиаторной. На наш взгляд, основным результатом кинетической активации аспартоацилазы является возникновение динамической волны синтеза глутаминовой кислоты - одной из основных нейромедиатов центральной нервной системы (ЦНС).

В работе удаётся проследить путь внешнего сигнала к химическим процессам в нервной ткани.
Это достаточно медленные процессы, цикл которых имеет диапазон десятков секунд. Однако эти процессы играют принципиальную роль в функционировании центральной нервной системы. По своей функциональной значимости исследуемый процесс направлен на автостабилизацию системы на ресурсное энергетическое и нейромедиаторное обеспечение ЦНС.

Источник финансирования. Работа поддержана Российским научным фондом (грант № 18-13-00030).

\section{СПИСОК ЛИТЕРАТУРЫ}

1. Stagg C., Rothman D. Magnetic Resonance Spectroscopy: Tools for Neuroscience Research and Emerging Clinical Applications. N.Y.: Acad. Press, 2013. $358 \mathrm{p}$.

2. Bottomley P.A., Griffiths J.R. Handbook of Magnetic Resonance Spectroscopy In vivo: MRS Theory, Practice and Applications. Chichester: Wiley, 2016. $1232 \mathrm{p}$.

3. Семенова Н.А., Ахадов Т.А., Петряйкин А.В., Сидорин С.С., Луковенков А.В., Варфоломеев С.Д. // Биохимия. 2012. Т. 77. № 4. С. 493-500.

4. Fox P.T., Raichle M.E. // Proc. Natl. Acad. Sci. USA. 1986. V. 83. P. $1140-1144$.

5. Matthews P., Hampshire A. // Neuron. 2016. V. 91. № 3. P. 511-528.

6. DeYoe E.A., Raut R.V. // Neuroimaging Clin. N. Amer. 2014. V. 24. № 4. P. 573-584.

7. Ублинский М.В, Семенова Н.А., Ахадов Т.А., Мельников И.А., Варфоломеев С.Д. // Изв. АН. Сер. хим. 2015. № 2. С. 451-458.

8. Coq J.Le, An H.J., Lebrilla C., Viola R.E. // Biochemistry. 2006. V. 45. P. 5878-5884.

9. Kots E.D., Khrenova M.G., Lushchekina S.V., Varfolomeev S.D., Grigorenko B.L., Nemukhin A.V. // J. Phys. Chem. B. 2016. V. 120. P. 4221-4231.

10. Варфоломеев С.Д., Кои Е.Д., Хренова М.Г., Лушекина С.В., Немухин А.В. // ДАН. 2017. Т. 474. № 4. C. $444-447$.

11. Kots E.D., Lushchekina S.V., Varfolomeev S.D., Nemukhin A.V. // J. Chem. Inf. Model. 2017. V. 57. P. 1999-2008.

12. Khrenova M.G., Kots E.D., Varfolomeev S.D., Lushchekina S.V., Nemukhin A.V. // J. Phys. Chem. B. 2017. V. 121. P. 9389-9397.

13. Варфоломеев С.Д., Гуревич К.Г. Биокинетика. М.: Фаир-Пресс, 1999. 720 с.

14. Жаботинский А.М. Концентрационные волны. М.: Наука, 1974. 179 с. 


\title{
KINETICS OF CHEMICAL PROCESSES IN THE HUMAN BRAIN. TRIGGER EFFECT AND SELF-STABILIZATION OF N-ACETYLASPARTIC ACID
}

\author{
Corresponding Member of the RAS S. D. Varfolomeev, \\ N. A. Semenova, V. I. Bykov, S. B. Tsybenova
}

Received August 1, 2018

\begin{abstract}
A kinetic model was proposed for the response of nerve tissue to an external signal stimulus. The model is based on the views of a multistep and non-linear nature of the dynamic variation of the concentrations of $N$-acetylaspartic acid and $N$-acetylaspartate in the human nerve tissue. The substrate inhibition effect in this system is a necessary factor for the self-stabilization of $N$-acetylaspartate as a key brain metabolite. The existence of three stationary states accounts for the trigger behavior of the system.

Keywords: human brain, chemical processes, kinetics, trigger effect, $\mathrm{N}$ acetylaspartic acid.
\end{abstract}

